\title{
Author Correction: Removal of deep-sea sponges by bottom trawling in the Flemish Cap area: conservation, ecology and economic assessment
}

\section{K. Pham, F. J. Murillo, C. Lirette, M. Maldonado, A. Colaço, D. Ottaviani \& E. Kenchington}

Correction to: Scientific Reports https://doi.org/10.1038/s41598-019-52250-1, published online 01 Novenber 2019

The original version of this Article contained errors in the Abstract.

"Sponge biomass surfaces created from research survey data using both random forest modeling and a gridded surface revealed 231,140 t of sponges in the area. About $65 \%$ of that biomass was protected by current fisheries closures."

now reads:

"Sponge biomass surface created from research survey data using random forest modeling revealed 231,136t of sponges in the area. About $42 \%$ of that biomass was protected by current fisheries closures."

This error has now been corrected in the PDF and HTML versions of the Article.

(c) (i) Open Access This article is licensed under a Creative Commons Attribution 4.0 International License, which permits use, sharing, adaptation, distribution and reproduction in any medium or format, as long as you give appropriate credit to the original author(s) and the source, provide a link to the Creative Commons license, and indicate if changes were made. The images or other third party material in this article are included in the article's Creative Commons license, unless indicated otherwise in a credit line to the material. If material is not included in the article's Creative Commons license and your intended use is not permitted by statutory regulation or exceeds the permitted use, you will need to obtain permission directly from the copyright holder. To view a copy of this license, visit http://creativecommons.org/licenses/by/4.0/.

(C) The Author(s) 2020 